\title{
ANALISIS GAYA BAHASA DALAM NOVEL DENGJI KARYA ZHAO SHULI
}

\author{
浅谈赵树理的小说作品
}

\author{
Andyni Khosasih《登记》 \\ Chinese Department, Faculty of Language and Culture, Bina Nusantara University, \\ Jln. Kemanggisan Ilir III No. 45, Kemanggisan/Palmerah, Jakarta Barat 11480 \\ andyni_khosasih@binus.ac.id
}

\begin{abstract}
This paper discusses the language and style used in Novel entitled "Dengji", one of the famous novels written by Zhao Shuli. This paper also discusses deeper about the content of the novel, the framework and the characters in the novel. It is found that first, the writer uses simple language and easy to understand. The objective of the writer to use simple language is because it is objected to the farmers with lower level of education. Second, the frame of the novel is clear. Therefore, the readers can easily follow the thought and ideas of the writer. Third, the women characters in this novel are divided into two types. The first type is the ones who keep the feudalism view, and the other is the one who are against the view.
\end{abstract}

Keywords: novel, language, style, characters, framework, writing style

\section{内容摘要}

《登记》是赵树理创造的小说之一。 《登记》反映当时农民的生活及思想。此论文分析《登记》里 的内容 (罗汉钱、眼力、不准登记、谁该检讨) 、使用语言、结构、创作风格及主要人物形象。通过分 析后, 笔者得出结论: 一、赵树理在《登记》使用通俗易懂的语言。目的是为了农民们能看懂他的小 说; 二、《登记》的结构非常清楚。这样作者更容易传播他的思想或想告诉大家的信息因为读者看懂小 说；三、《登记》里的女性可分成两类：（一）保留并坚持封建思想、（二）反对封建思想。

关键词：小说内容，使用语言，创作风格，人物形象，结构 


\section{前言}

赵树理（1906-—1970）, 原名赵树礼, 山西沁水县尉迟村人。现代著名小说家、人 民艺术家。1906 年 9 月 24 日出生在山西省沁水县贫苦农民家庭, 在农民中长大, 他不仅 了解农民, 也热爱和深通农民的艺术。青年时代外出求学和流浪, 曾就学于长治的山西第 四师范学院, 接触到新文学和左翼文学, 受到影响。他因出生贫寒、非常了解农民的生活, 所以在创造作品中常把农民作为主体, 如《登记》。因此, 笔者选择 “浅谈赵树理的小说 作品一一《登记》”作为论文题目。目的为了解当时社会农民的生活及思想。

\section{浅谈赵树理的小说作品—《登记》}

\section{内容}

《登记》是赵树理 1950 年 6 月 5 日发表的第一篇短篇小说。赵树理把《登记》分成四个 部分: 一、罗汉钱; 二、眼力; 三、不准登记; 四、谁该检讨?

\section{(一) 罗汉钱}

罗汉钱是《登记》的第一个部分。在这里, 赵树理首先把罗汉钱与小飞哦的来历交代得非 常清楚。这使读者知道罗汉钱到底是什么样的东西, 为何人们把张木匠的爱人叫作小飞哦。作 者讲完罗汉钱与小飞哦的来历之后，才开始叙述张木匠一家人的生活和所发生的事情。可说作 者很清楚什么时候该交代什么，什么事情不该交代。正如赵树理在小说里所说的:

“有些事情不到交代的时候，早早交代出来是累赘；到了该交代的时候，想不交代也不行。”1

《登记》在此所描述的婚姻是包办婚姻。张木匠与小飞哦的婚姻为代表。这是封建社会的 思想。当时结婚对象是父母之命, 自己根本没有权力说不愿意, 更有谈自由恋爱。其实小飞哦 已有对象, 就是保安, 但因她父母把她许配给张木匠, 虽然有一千个不愿意, 可到是最后还是 嫁给了张木匠。小飞哦嫁给张木匠后, 还是忘不了保安。她一直把保安送给她的罗汉钱藏在身 边。张木匠最初不知为何小飞哦对他那么冷淡。他知道原因之后显然很生气, 可也不听母亲叫 他打小飞哦的理由。虽当初不打, 可后来还是用锯梁子把小飞哦狠狠地打, 打到没力气才停下 来。张木匠的母亲嫁给老木匠之前也是自由恋爱, 可因当时不允许自由恋爱, 所以只能听父母 之命, 嫁给老木匠。她以前被老木匠挨打过, 就是用锯梁子。她以同样的方法建议张木匠教训 小飞哦，希望小飞哦能知错能改。可见张木匠的母亲还是封建思想。

《登记》还提到了艾艾的罗汉钱。艾艾是张木匠和小飞哦的女儿，也是他们唯一的孩子。 当小飞哦看到艾艾的罗汉钱时, 她就想起往事, 决定尽快替艾艾找个婆家, 免得发生不愉快的 事情。可说她与婆婆一样, 都是封建思想。这样, 艾艾的婚姻也是包办婚姻, 自己无法决定自 己的未来。她和母亲、奶奶有同样的命运。从这儿我们可以了解当时女性虽然自己受到不好的 对待, 社会地位远远比不上男性, 但她们本身都认为这是天经地义的事, 更可悲的是她们却亲 自提倡或传播封建思想。

\section{（二） 眼力}

小飞哦因不愿意看到艾艾像她过着像犯人一样的生活, 所以当她知道艾艾也有罗汉钱时, 她就决定赶快替艾艾找个婆家。她本来已愿意把女儿嫁给民事主任的外甥, 可后来就拒绝了。 小飞哦会拒绝这门婚姻是因为她听到了五婶和民事主任一家人的谈话。

\footnotetext{
${ }^{1}$ 王庆生、林志浩，中国现当代文学作品选读，高等教育出版社，2006 年
} 
“五婶说：改得了! 人是苦虫！痛痛打一顿以后就没事了! 老汉说: 生就的骨头, 哪里打得过来? 五婶说：打得过来，打得过来！小飞哦那时候，还不是张木匠一顿锯梁子打过来的？”2

小飞哦听到了这番话才恍然觉悟若把艾艾嫁给民事主任的外甥，艾艾的命运就会跟她一样。 此时她不再保留封建思想。燕燕知道小飞哦拒绝这门婚事时, 就为艾艾和小晚作媒。谁想到小 飞哦竟然同意了。从这里能看出小飞哦不再反对自由恋爱, 甚至夸艾艾的眼力不错。从以上分 析得知小飞哦经过为女儿找婆家时发生了极大的改变, 就是从封建思想改为开放。

此外, 在《登记》里也能看出艾艾, 小晚与燕燕反对封建思想, 支持自由恋爱。他们为了 追求幸福而抗议, 这与其他年轻人不一样。虽然很多年轻人不愿意和父母所指定的对象结婚, 但到最后还是顺从父母。

\section{（三） 不准登记}

在此讲到艾艾和小晚、燕燕和王旦去村公所登记的内容。王助理员都拒绝这两对年轻人。 他拒绝艾艾和小晚登记的原故是他们俩没有介绍信。民事主任不给介绍信是因为想让外甥娶艾 艾的企图。另外的原因是艾艾的生名不正。虽然艾艾和小晚已解释他们的父母都同意他们结婚 可王助理员还是不给登记。从这里可看出王助理员和其他人一样, 都是封建思想。他无法接受 自由恋爱的观念。

王助理员拒绝燕燕与王旦的登记是因为王旦认错人，以为艾艾是燕燕; 男方的岁数不实在。 实际上, 若王旦不犯这两个错误的话, 王助理员肯定给他们登记。因此, 可说王助理员与民事 主任一样, 不履行自己的任务。照理他们该好好检查想要登记的人的介绍信, 可他们却不这么 做。如：王助理员每次都会问同样的问题, 像 “你叫什么”, “你们是自愿吗？”， “为什么 愿意跟她（他）结婚？”。对王助理员的问题，来登记的人每次回答：“自己的名字”，“自 愿的”, “因为她 (他) 能劳动”。从人们的答案, 我们可知道实际上不少人来登记不是因愿 意结婚, 而是被强迫的。其实他也知道这些来登记的人当中, 很多人是被强迫的, 可因他是老 观念，所以到最后还是给他们登记。

另外, 王助理员和民事主任在 “身材” 与 “行为” 之间哪个比较重要, 他俩都选择 “身 材”。这能证明他们并不注重内在美, 只注重外表。再三, 这两个人属于官僚主义的官员。下 面句子能体现出王助理员和民事主任的官僚主义:

1. 民事主任

就很蛮得把墨盒盖子一盖说：任你们有天大的本事，这个介绍信我不 写！艾艾说：不写我们也要去登记！区上问起来我就请他们评一评这个理！“主任 说：不服劲你去试试！区上又不是不知道你们的好声名！”吵了半天，还是不给写， 他们只得走出来。

2. 王助理员

王助理员说：村里既然有报告，等调查调查再说吧！为什么还要检查 呢? 他们两个都没有结过婚, 和谁也没有麻烦！两个人又真正自愿, 还要检查什么 呢? 反正还得调查调查！这件事就这样了。

\footnotetext{
${ }^{2}$ 王庆生、林志浩, 中国现当代文学作品选读, 高等教育出版社, 2006 年

${ }^{3}$ 王庆生、林志浩, 中国现当代文学作品选读, 高等教育出版社, 2006 年

${ }^{4}$ 王庆生、林志浩, 中国现当代文学作品选读, 高等教育出版社, 2006 年
} 


\section{（四）谁该检讨?}

艾艾、燕燕和小晚从不放弃他们的理想。虽然他们拿不到介绍信, 无法登记, 但还是坚持 自己的思想，便等机会可以登记。艾艾和小晚还是无法结婚，直到中央人民政府公布了婚姻法 以后, 他们才能结婚。这对年轻人的婚姻被称为模范婚姻。因区里说是模范婚姻, 许多人有了 新的看法。艾艾和小晚的婚姻改变了人们的思想。人们对婚姻观念不再保留封建思想，其中一 个是燕燕的母亲。她亲自叫燕燕跟小进到区上去登记。

艾艾和小晚结婚时, 区上来了两个干部, 村上的干部差不多全体参加。这表明政府不反对 自由恋爱, 鼓励大家因真正自愿才去登记。从以上分析, 笔者得知《登记》的主要内容是提倡 自由恋爱, 自由婚姻, 自由选择结婚对象。这么做的人也不怕被人们看成声名不正的人因政府 已公布婚姻法, 主要是自愿的就可以结婚, 不需要经过父母或他人的同意。

另外, 《登记》以张家庄张木匠的老婆小飞哦和他们的女儿艾艾为主题, 小说里描写了小 飞哦与她婆婆和女儿艾艾三代女性的婚恋故事。小飞哦与她婆婆本来已有相好的, 可当时婚姻 对象是父母指定的, 所以无法和喜欢的人络成滕属。艾艾就和她母亲, 外婆不一样。她能与小 晚结婚是因为已有婚姻法和她的坚持。因此, 能阻拦他们结婚的因素已不存在。

\section{使用语言}

赵树理在《登记》使用通俗易懂的语言。这符合他写《登记》读者的对象。《登记》的主 要读者是农民。若赵树理使用精美的语言来写小说, 农民就看不懂他所写的小说因为大多数农 民都没受过高等教育, 甚至不少人是盲人。这样他就无法传达他所想告诉农民的信息。赵树理 因使用通俗易懂的语言, 识字的农民就看得懂。如此, 他们就会把小说的内容讲述给那些不识 字的农民。这样一来农民们都知道小说的内容。

\section{结构}

从结构方面来分析, 《登记》的结构十分清楚。首先作者先把罗汉钱交代清楚。许多人也 许认为不需要把罗汉钱描写的这么详细, 可笔者认为把罗汉钱交代清楚是必要的。罗汉钱在小 飞哦和艾艾生活中的影响非常大。母女俩都离不开它。小飞哦经常把罗汉钱暖到手心里, 贴到 脸上, 按到胸上, 衔到口里。每天晚上她都是离了罗汉钱睡不着觉。艾艾与她母亲一样。当她 发现她的罗汉钱不见时, 就到处找, 甚至一大早起床打扫屋子, 希望能找到罗汉钱。

作者讲完罗汉钱就开始进入小说的真正主体。赵树理先介绍核心人物, 张木匠一家人的生 活习惯与所发生的事情。作者先叙述艾艾和小晚、燕燕与小进的恋爱关系, 再描写这些年轻人 为追求自己的理想而拼命奋斗。小说里也提到了燕燕因无奈才答应嫁给一个未见过的男性。赵 树理在叙述《登记》的情节都很仔细。这样读者一看就懂小说内容。小说的每个情节必须很仔 细, 因为主要读者是农民。赵树理写《登记》是为农民而写的。当时中央刚宣布婚姻法。因此, 作者就写《登记》, 目的是为了农民们能意识到婚姻法的存在, 也希望他们对封建思想的观念 有所改变。

\section{创作风格}

从《登记》我们能看出赵树理的创作风格。《登记》描写农民的现实问题。赵树理在小说 中使用通俗易懂的语言的目的是让农民看懂小说内容, 希望农民们意识到婚姻法的存在。他这 么做不完全为农民，可也为共产党服务。赵树理是个党兄。 


\section{主要人物形象}

\section{（一） 小飞哦}

小飞哦是个贤妻良母的女性。刚结婚时, 虽然不爱丈夫, 但她还是履行一个身为妻子该做 的任务。她能相夫教子, 把女儿照顾得很好。她十分疼爱自己的女儿。小飞哦是个中年妇女, 具有浓厚的封建思想。她认为孩子的婚姻是父母之命。因此当她的父母让她嫁给张木匠时, 虽 然心里很不愿意, 但也不说出来。这样使她付出惨痛的代价。她只能在夜深人静之时回忆往事, 过着不幸福的日子。小飞哦你年轻时无法与自己喜欢的人相守一生, 可当她发现女儿有了对象 时, 反而决定找个好婆家, 把艾艾嫁出去。从这方面, 我们能看出小飞哦很明显受到封建婚姻 制度的影响。从其它角度来分析, 她这么做也是为了女儿, 希望女儿不像她过着被人们当做声 名不正的女性。小飞哦在婚姻方面算是受害者, 可她是不清醒的, 直到她亲耳听到他们打算用 锯梁子对艾艾狠狠打一顿时, 她才醒悟。小飞哦不愿意看到女儿与她受同样的苦。这样她对 “父母之命” ，媒妁之言极为反感，否定了民事主任外甥与艾艾的婚事，同意艾艾与自己的如 愿良君结婚。

\section{（二）艾艾}

艾艾是个美丽活泼的女孩。艾艾是个好女儿。因没有兄弟姐妹, 每天都帮助母亲做家务, 如: 打扫房子, 洗碗等等。她很清楚自己的人生目标, 与当时的人们恰恰相反。艾艾反对封建 制度, 敢追求自己的梦想而付出代价。在追求梦想时从不气馁, 从不放弃。艾艾除了是一个好 女儿以外, 也是个值得交往的朋友。她属于有福同享, 有难同当的朋友。她与燕燕是好友。她 们互相帮助，彼此给对方支持与鼓励。

\section{（三） 燕燕}

燕燕是个活泼的姑娘。她与艾艾一样, 有自己的梦想。她们俩的共同点是：一、自由恋 爱; 二、敢追求自己的梦想; 三、从不放弃。这与当时人们恰恰相反。人们因不想被称名声不 正而不敢自由恋爱, 更何况追求自己的梦想。燕燕与艾艾的区别是燕燕的父母不同意女儿与自 己的恋人结婚。燕燕的母亲甚至威胁她若还固执和小进结婚就会自杀。从友情角度来分析, 燕 燕是个知心朋友。她尽力帮助艾艾得到小飞哦的支持, 好让艾艾能和小晚结婚。其实她自己面 临着不少困难, 家长不同意他与小进结为夫妻。

\section{结语}

从分析后，笔者得出下面结论:

一、赵树理在《登记》使用通俗易懂的语言。目的是为了农民们能看懂他的小说。

二、《登记》的结构非常清楚。这样作者更容易传播他的思想或想告诉大家的信息因为读者 看懂小说。

三、《登记》体现出赵树理的创作风格。

四、《登记》里的女性可分成两类:

（一）保留并坚持封建思想。

（二）反对封建思想。 


\section{参考文献}

钱理群、温儒敏、吴福辉，(1998) 《中国现代文学三十年》，北京大学出版社 谢冕、洪子诚（2002）《中国当代文学作品精选 1949-1999》，北京大学出版社 王庆生、林志浩，（2006）《中国现当代文学作品选读》，高等教育出版社 童庆炳，（2005）《文学理论教程》，高等教育出版社

朱栋霖、丁帆、朱晓进（2006）《中国现代文学史 1917-1997 上册》，高等教育出版社 朱栋霖、丁帆、朱晓进（2006）《中国现代文学史 1917-1997 上册》, 高等教育出版社 尹缉熙，（2007）《文学鉴赏》，高等教育出版社 